\title{
A new strategy to intrinsically protect refractory metal based alloys at ultra high temperatures
}

\author{
Bronislava Gorr ${ }^{\mathrm{a}}$, Franz Müller ${ }^{\mathrm{a}}$, Steven Schellert ${ }^{\mathrm{a}}$, Hans-Jürgen Christ ${ }^{\mathrm{a}}$, Hans Chen ${ }^{\mathrm{b}}$, \\ Alexander Kauffmann ${ }^{\mathrm{b}}$ and Martin Heilmaier ${ }^{\mathrm{b}}$ \\ Bronislava Gorr, Institut für Werkstofftechnik, Universitaet Siegen, Germany, \\ gorr@ifwt.mb.uni-siegen.de, +492717404653
}

Franz Mueller, Institut für Werkstofftechnik, Universitaet Siegen, Germany, franz.mueller@uni-siegen.de, +492717404653

Steven Schellert, Institut für Werkstofftechnik, Universitaet Siegen, Germany, steven.schellert@uni-siegen.de, +492717403121

Hans-Juergen Christ, Institut für Werkstofftechnik, Universitaet Siegen, Germany, christ@ifwt.mb.uni-siegen.de, +492717404658

Hans Chen, Institut für Angewandte Materialien - Werkstoffkunde, Karlsruher Institut für

Technologie (KIT), Germany, hans.chen@kit.edu, +4972160846462

Alexander Kauffmann, Institut für Angewandte Materialien - Werkstoffkunde, Karlsruher Institut für Technologie (KIT), Germany, alexander.kauffmann@ @it.edu, +49 72160842346

Martin Heilmaier, Institut für Angewandte Materialien - Werkstoffkunde, Karlsruher Institut für Technologie (KIT), Germany, martin.heilmaier@kit.edu, +49 72160846594

\author{
${ }^{a}$ Institut für Werkstofftechnik, Universität Siegen, Siegen, Germany; \\ ${ }^{\mathrm{b}}$ Institut für Angewandte Materialien, Karlsruher Institut für Technologie (KIT), Karlsruhe, \\ Germany \\ *Corresponding author
}

\begin{abstract}
Poor oxidation resistance represents one of the main shortcomings of refractory metal based alloys. This work shows an innovative way to intrinsically protect such materials. Our approach relies on the alloying with $\mathrm{Cr}$ and $\mathrm{Ta}$ allowing the formation of $\mathrm{CrTaO}_{4}$. The $\mathrm{CrTaO}_{4}$ scale formed on the novel refractory equiatomic high entropy alloy Ta-Mo-Cr-Ti-Al reveals a unique combination of the following properties: (i) easy formation in a wide temperature range from $500^{\circ} \mathrm{C}$ to $1500^{\circ} \mathrm{C}$, (ii) excellent adherence after cooling, (iii) low growth rates, and (iv) wide stability range of the stoichiometric composition that suppresses the formation of non-protective oxides.
\end{abstract}

Keywords: High temperature materials, Refractory high entropy alloys, Oxidation resistance, Protective oxides, $\mathrm{CrTaO}_{4}$

\section{Introduction}


Because of their high melting temperatures, refractory metal (RM) based alloys have been considered for decades as potential candidates to substitute Ni-base superalloys in gas turbines aiming at a substantial increase of the turbine thermodynamic efficiency. Unfortunately, refractory metals exhibit poor oxidation resistance forming, depending on temperature, either quickly growing non-protective or volatile oxides causing a fast disintegration of the material [1]. To the best of our knowledge, so far no oxide scale was established on refractory metal-based materials that guarantees protective properties in air in a temperature range from $500^{\circ} \mathrm{C}$ up to $1500^{\circ} \mathrm{C}[1,2]$. Recently introduced Refractory High Entropy Alloys (RHEAs) may enable a breakthrough towards higher operating temperatures as they possess exceptionally attractive mechanical properties [3, 4]. However, none of the RHEAs reported in the literature forms continuous protective oxides such as $\mathrm{Al}_{2} \mathrm{O}_{3}, \mathrm{Cr}_{2} \mathrm{O}_{3}$ or $\mathrm{SiO}_{2}$ known to insure the required enduring oxidation resistance in a wide temperature range [5-8]. Most of RHEAs form complex oxides which possess rather moderate protective properties [9-11]. It should, however, be mentioned that some of them, e.g. $\mathrm{CrNbO}_{4}$ and especially $\mathrm{CrTaO}_{4}$, exhibit significant protectiveness during high temperature oxidation [11]. In fact, these oxides were observed in different alloy systems such as $\mathrm{Cr}-\mathrm{Ta}$ and $\mathrm{Cr}-\mathrm{Nb}$ [1215]. Recently, the beneficial effect of the complex oxides $\mathrm{CrNbO}_{4}$ as well as $\mathrm{CrTaO}_{4}$ was found in studies investigating high temperature oxidation behavior of RHEAs. Butler et al. explained the nearly parabolic kinetics by the formation of $\mathrm{CrNbO}_{4}$ on the RHEA Nb-Ti-ZrCr [11]. Remarkable protectiveness of $\mathrm{CrTaO}_{4}$ was recently reported by Lo et al. while studying the oxidation behavior of the RHEA based on the alloy system Al-Si-Ti-Cr-Nb-MoTa [16]. Apparently, these complex oxides seem to offer a unique opportunity to provide reasonable protectiveness for RHEAs.

In this paper, we present experimental proof that RHEAs can be intrinsically protected by a thermally growing scale consisting of complex oxide(s) which provides protectiveness not only at temperatures beyond the thermal capability of the best Ni-base superalloys (> $1200^{\circ} \mathrm{C}$ ), but also prevents from the so-called "pesting" phenomenon, i.e. the fast disintegration of the metallic substrate due to intergranular oxidation at moderate temperatures (around 500 to $800^{\circ} \mathrm{C}$ ) for which RM alloys are well-known [17, 18].

The chemical composition of the equiatomic RHEA Ta-Mo-Cr-Ti-Al investigated in this study was chosen on the basis of the following considerations: (i) Ta and Mo were selected to ensure a high melting point and to provide good mechanical strength, (ii) $\mathrm{Cr}$ and $\mathrm{Al}$ were added to ensure the oxidation resistance, and (iii) $\mathrm{Ti}$ (in addition to $\mathrm{Al}$ ) should reduce the alloy density. On grounds of the chemical composition, this alloy includes 60 at.\% of refractory metals, i.e. Ta, Mo and $\mathrm{Cr}$. According to our thermodynamic calculations, the solidus temperature of the alloy is about $2100^{\circ} \mathrm{C}$. In contrast to other approaches for RMbased materials where intermetallic phases like silicide (in e.g. Mo- and Nb-based alloys) containing passivating elements (e.g. Si in Mo- and Nb-based alloys) are utilized to protect other non-protective microstructural parts, the (almost) single-phase solid solution form of RHEAs ensures a homogeneous distribution and activity of passivating elements throughout the surface. No further microstructural optimization and manipulation of the oxides scale is needed (e.g. viscosity of the scale by adding B to Mo-based materials).

\section{Material and methods}


The equiatomic RHEA Ta-Mo-Cr-Ti-Al was manufactured by arc melting. The elements Ta, Mo, Cr, Ti and Al possess nominal purities of 99.9, 99.96, 99, 99.8 and 99.9\%, respectively. All these elements were mixed and placed in the vacuum chamber of an AM/0.5 arc melting furnace by Edmund Bühler GmbH (Germany). The furnace chamber was alternately pumped down to a pressure of $5 \cdot 10^{-2}$ mbar and flooded with Ar up to ambient pressure for three times. A high vacuum of $1 \cdot 10^{-4}$ mbar was finally established. The value of the working Ar pressure for the melting operation was around $600 \mathrm{mbar}$. The manufactured ingots were flipped, remelted for at least five times and cast into a water-cooled, rod-shaped $\mathrm{Cu}$ mold with a diameter of $12 \mathrm{~mm}$ and a length of $60 \mathrm{~mm}$. A homogenization treatment was performed in an Ar atmosphere at $1500^{\circ}$ for $20 \mathrm{~h}$. The heating and cooling rate were $250 \mathrm{~K} / \mathrm{h}$ each.

To perform oxidation tests on the RHEA Ta-Mo-Cr-Ti-Al, the ingots were cut by electrical discharge machining (EDM) to dimensions of $5 \mathrm{~mm} \times 5 \mathrm{~mm} \times 2 \mathrm{~mm}$, polished up to grit P1200 and finally ultrasonically cleaned in ethanol directly before high temperature exposure. The samples of the Ni-based alloy CMSX-4 for the comparative studies (provided by Dr. Julian Mueller, Micro- and Nanoanalytics Group, Institute of Materials Science, University of Siegen) were prepared analogously. Oxidation tests were performed isothermally in a Rubotherm thermogravimetric system at $500^{\circ} \mathrm{C}, 1000^{\circ} \mathrm{C}, 1300^{\circ} \mathrm{C}, 1400^{\circ} \mathrm{C}$ and $1500^{\circ} \mathrm{C}$ for 12 hours in air. The crystal structures of the oxides formed were analysed using X-ray diffraction (XRD). The XRD measurements were conducted using an X'Pert Pro MPD diffractometer operating in Bragg-Brentano geometry with $\mathrm{Cu}-\mathrm{K} \alpha$ radiation. To study the oxide morphology, a Focused Ion Beam - Scanning Electron Microscope (FIB-SEM) DualBeam system of type FEI Helios Nanolab 600 was utilized which is equipped with backscatter electron (BSE) imaging, energy dispersive X-ray spectroscopy (EDX) and electron backscatter diffraction (EBSD).

\section{Results and discussion}

The results of the oxidation tests performed on the equiatomic RHEA Ta-Mo-Cr-Ti-Al at $900^{\circ} \mathrm{C}, 1000^{\circ} \mathrm{C}$ and $1100^{\circ}$ were presented and discussed in ref. [19]. In the current study, the range of temperature is expanded to $500^{\circ} \mathrm{C}, 1300^{\circ} \mathrm{C}, 1400^{\circ} \mathrm{C}$ and $1500^{\circ} \mathrm{C}$. To quantitatively assess the oxidation resistance of our alloy, analogous experiments were carried out with the single crystalline Ni-based superalloy CMSX-4. Figure 1a compares macroscopic images of the alloy Ta-Mo-Cr-Ti-Al and the alloy CMSX-4 oxidized continuously for $12 \mathrm{~h}$ at $500^{\circ} \mathrm{C}$, $1300^{\circ} \mathrm{C}, 1400^{\circ} \mathrm{C}$ and $1500^{\circ} \mathrm{C}$. Obviously, both alloys maintain their original shape, particularly, the sharp edges of the cuboids are still visible at temperatures up to $1300^{\circ} \mathrm{C}$ indicating excellent oxidation resistance. Beyond that, the alloy CMSX-4 starts to melt at $1400^{\circ} \mathrm{C}$. The alloy Ta-Mo-Cr-Ti-Al shows, on the contrary, a remarkable resistance to corrosion attack even at temperatures up to $1500^{\circ} \mathrm{C}$. It is noteworthy that the color of the outer oxide scale changes from gray $\left(1300^{\circ} \mathrm{C}\right)$ to greenish orange $\left(1400^{\circ} \mathrm{C}\right)$ and finally to green $\left(1500^{\circ} \mathrm{C}\right)$. XRD investigations in combination with EDS analysis of the sample surface (results are not shown here) reveal that the outer layer consists of $\mathrm{TiO}_{2}, \mathrm{Cr}_{2} \mathrm{O}_{3}$ and $\mathrm{Al}_{2} \mathrm{O}_{3}$. While the color of $\mathrm{TiO}_{2}$ may change depending on dopant from yellow to orange [20], $\mathrm{Cr}_{2} \mathrm{O}_{3}$ and $\mathrm{Al}_{2} \mathrm{O}_{3}$ usually exhibit green [21] and gray color [22], respectively. Detailed microstructural investigations of the sample surfaces show that the ratio of these oxides and, 
consequently, the oxide color varies depending on the oxidation temperature. Moreover, the color of the scale and, thus, the ratio of $\mathrm{TiO}_{2}, \mathrm{Cr}_{2} \mathrm{O}_{3}$ and $\mathrm{Al}_{2} \mathrm{O}_{3}$ may even change within one sample (see, e.g. the surface of the sample after oxidation at $1400^{\circ} \mathrm{C}$, Fig. 1a). The results of oxidation tests performed in our earlier study at $1000^{\circ} \mathrm{C}$ revealed that the outer scale did not change markedly in terms of the constituting oxides and their ratio even after extended oxidation up to $300 \mathrm{~h} \mathrm{[19].} \mathrm{We} \mathrm{thus} \mathrm{anticipate} \mathrm{a} \mathrm{similar} \mathrm{behavior} \mathrm{at} \mathrm{the} \mathrm{higher} \mathrm{temperatures}$ tested here, although experimental proof should be left for future work.

However, the most remarkable finding was made at the lower end of the temperature range at $500^{\circ} \mathrm{C}$, neither pesting that is typical of some refractory metal-based phases (e.g. $\mathrm{MoSi}_{2}$ ) [17] nor pesting-like phenomenon (accelerated formation of simple oxides with unfavorable volumetric expansion) often observing in RHEAs [23] occur. It should also be pointed out that the same holds true for our alloy when tested at the higher end of the pesting regime, i.e. at $900^{\circ} \mathrm{C}$, see ref. [19]. A deeper insight into the protective properties of the oxide scales is given in Figs. 1b and 1c. Apparently, the oxide layers formed on the alloy CMSX-4 tend to be prone to spallation during cooling indicating the development of high stresses in the oxide scales. The oxide layer formed on the alloy Ta-Mo-Cr-Ti-Al, however, yields no indications of macroscopic cracks and remains perfectly adherent.

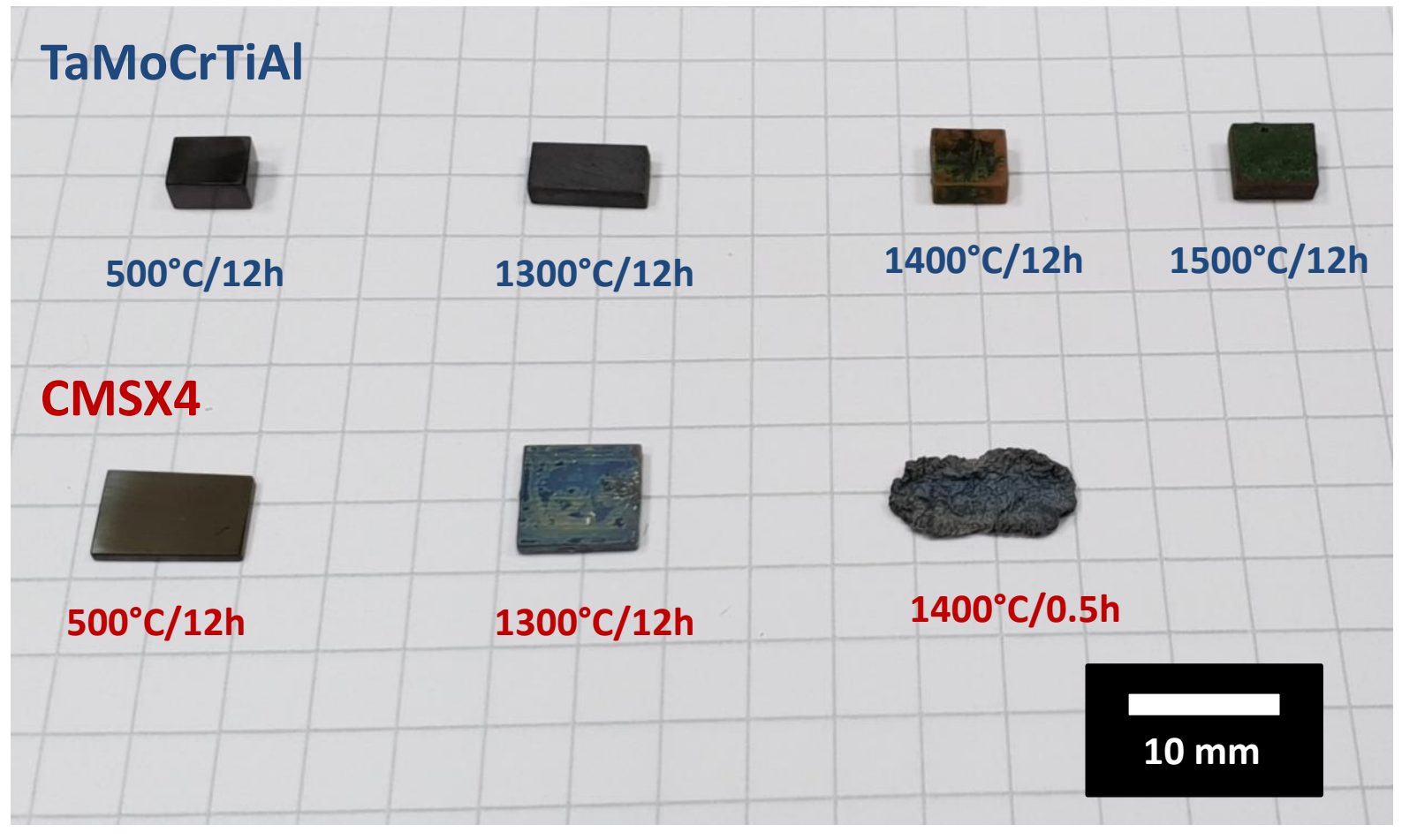




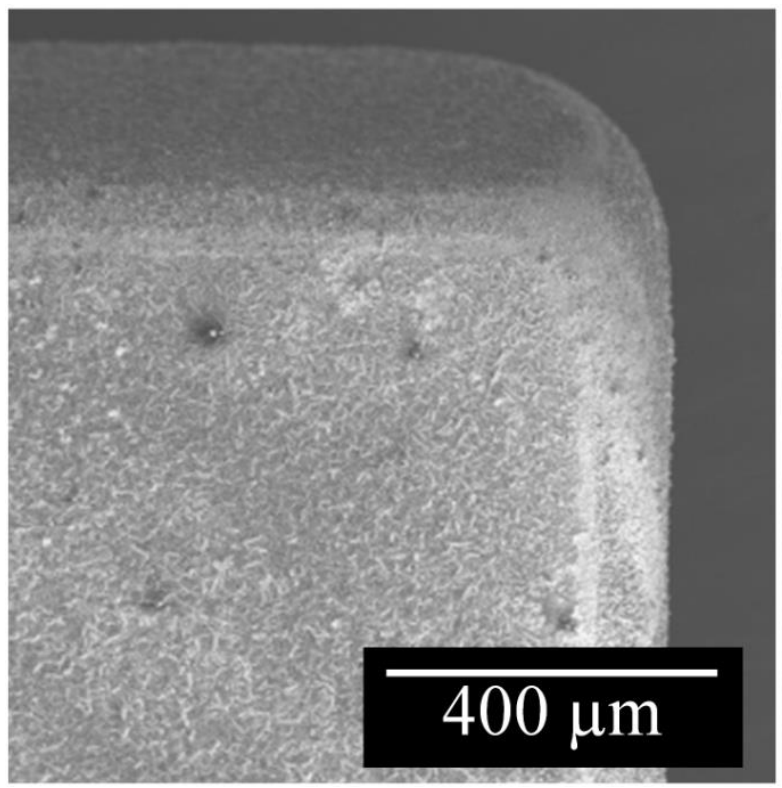

b

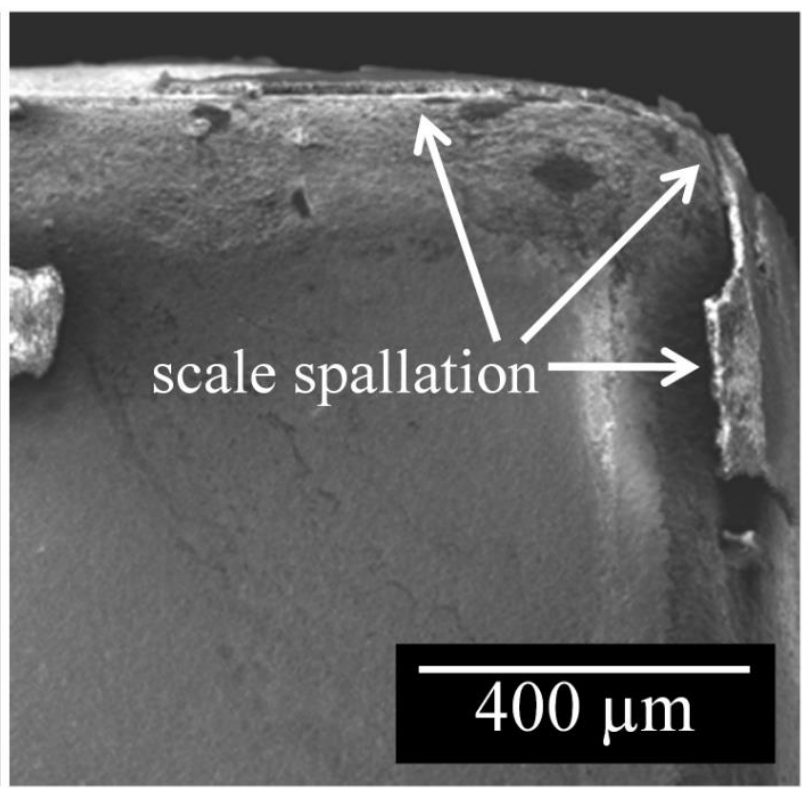

c

Fig. 1: Qualitative comparison of the oxidation behavior of the equiatomic HEA Ta-Mo-CrTi-Al with the Ni-based alloy CMSX-4. a, macroscopic micrographs of the alloys oxidized at $500^{\circ} \mathrm{C}, 1300^{\circ} \mathrm{C}, 1400^{\circ} \mathrm{C}$ and $1500^{\circ} \mathrm{C}$. b, view of a sample edge of the alloy Ta-Mo-Cr-Ti-Al oxidized at $1300^{\circ} \mathrm{C}$ for $12 \mathrm{~h}$. c, view of a sample edge of the alloy CMSX-4 oxidized at $1300^{\circ} \mathrm{C}$ for $12 \mathrm{~h}$.

To assess the oxidation kinetics in detail, specific mass change of the alloy Ta-Mo-Cr-Ti-Al was recorded continuously at temperatures of $1000^{\circ} \mathrm{C}, 1300^{\circ} \mathrm{C}, 1400^{\circ} \mathrm{C}$ and $1500^{\circ} \mathrm{C}$. Note that temperatures greater than $1200^{\circ} \mathrm{C}$ are beyond the current maximum metal temperature of Ni-base superalloys in gas turbine applications. The oxidation curves exhibit the following remarkable features at all temperatures: (i) very moderate mass gains indicating slow growth rates and (ii) no signs of spallation suggesting well-adhering oxide scales. Further, no signs of evaporation of Mo and Ta oxides were detected. Numerous studies report on the excellent oxidation resistance of Ni-based superalloys in a wide temperature range, see e.g. [24, 25]. The results of the oxidation experiments on the alloy CMSX-4 reveal even lower specific mass change compared to those of our HEA - only $0.32 \mathrm{mg} / \mathrm{cm}^{2}$ was recorded after $12 \mathrm{~h}$ of oxidation at $1300^{\circ} \mathrm{C}$. However, beyond this temperature, this alloy cannot be used/tested due to incipient melting (see Fig. 1a). 


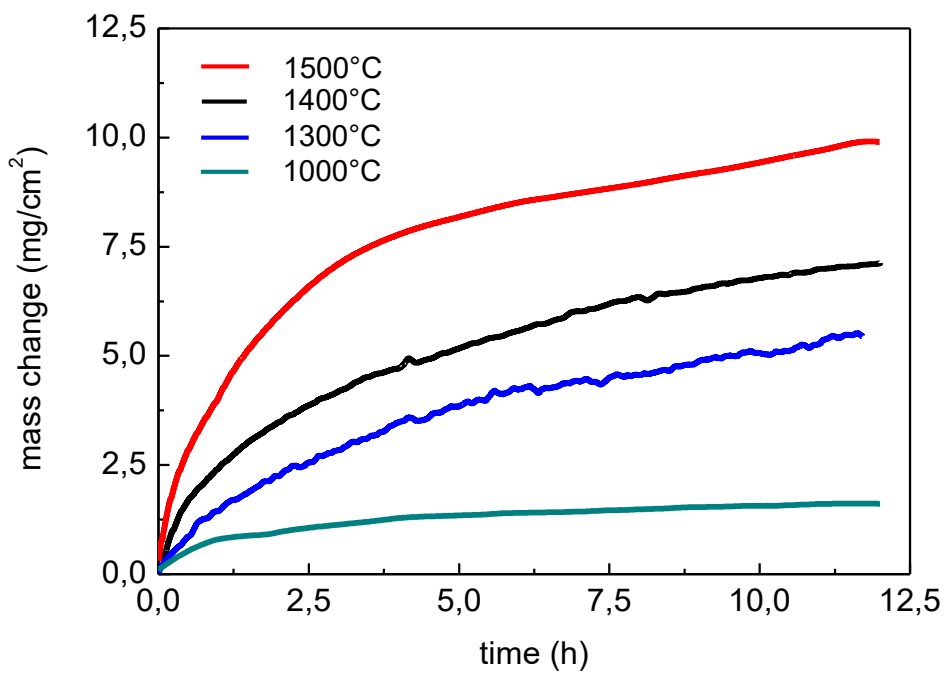

Fig. 2: Mass change of Ta-Mo-Cr-Ti-Al during isothermal oxidation at $1000^{\circ} \mathrm{C}, 1300^{\circ} \mathrm{C}$, $1400^{\circ} \mathrm{C}$ and $1500^{\circ} \mathrm{C}$.

Figure 3a shows exemplary cross-sectional micrographs of oxidized samples of the alloy TaMo-Cr-Ti-Al at $1300^{\circ} \mathrm{C}$ and $1500^{\circ} \mathrm{C}$ obtained by SEM in BSE mode. Further in-depth microstructural investigations employing energy dispersive X-ray spectroscopy, X-ray diffraction and transmission electron microscopy (not shown here) techniques confirm the formation of an outermost $\mathrm{TiO}_{2}$ layer and an underlying continuous $\mathrm{CrTaO}_{4}$-based layer (appears light gray in contrast) with embedded $\mathrm{Cr}_{2} \mathrm{O}_{3}$ and $\mathrm{Al}_{2} \mathrm{O}_{3}$ particles on the alloy Ta-MoCr-Ti-Al. $\mathrm{Al}_{2} \mathrm{O}_{3}$ and $\mathrm{Cr}_{2} \mathrm{O}_{3}$ cannot provide reliable oxidation protectiveness as they do not form fully continuous scales. $\mathrm{TiO}_{2}$, in general, does not possess protective properties. Obviously, the formation of the $\mathrm{CrTaO}_{4}$-based oxide layer accounts for the high oxidation resistance of Ta-Mo-Cr-Ti-Al. Considering the experimental results presented above, we believe that the oxidation mechanism at $1000^{\circ} \mathrm{C}$ as described in our recent study [19] also holds true for the temperatures relevant for this study. According to Mueller et al. [19], the formation and the growth of the $\mathrm{CrTaO}_{4}$-based oxide is governed by the inward (solid-state) diffusion of oxygen through this scale, thus determining the steady-state oxidation kinetics discussed in the next paragraph in the context of Fig. 4. The oxide $\mathrm{CrTaO}_{4}$, which possesses the rutile-type crystal structure, seems to exhibit the remarkable feature that this oxide is able to solve substantial amount of other elements, e.g. Ti and Al (see the EDX mappings in Fig. 3b). Other elements seem to participate in the constitution of $\mathrm{CrTaO}_{4}$ rather than forming their own oxides, hence, potentially suppressing the formation of non-protective and fast growing oxides such as e.g. $\mathrm{TiO}_{2}$ and $\mathrm{Ta}_{2} \mathrm{O}_{5}$. Similar features were reported in literature. Based on the results of the X-ray single crystal investigations, Petersen and Mueller-Buschbaum concluded that metal cations in the $\mathrm{CrTaO}_{4}$ are randomly distributed in the rutile-type structure [26]. Further, Kirnbauer et al. stated that the entropy effect in $(\mathrm{Al}, \mathrm{Cr}, \mathrm{Nb}, \mathrm{Ta}, \mathrm{Ti}) \mathrm{O}_{2}$ high-entropy oxide thin films may lead to a significant stabilization of the rutile structure [27]. It should be mentioned that nitrogen (in addition to oxygen) diffuses inward through the $\mathrm{CrTaO}_{4}$ scale contributing to the formation of a pronounced zone of internal corrosion (see Fig. 3a). 


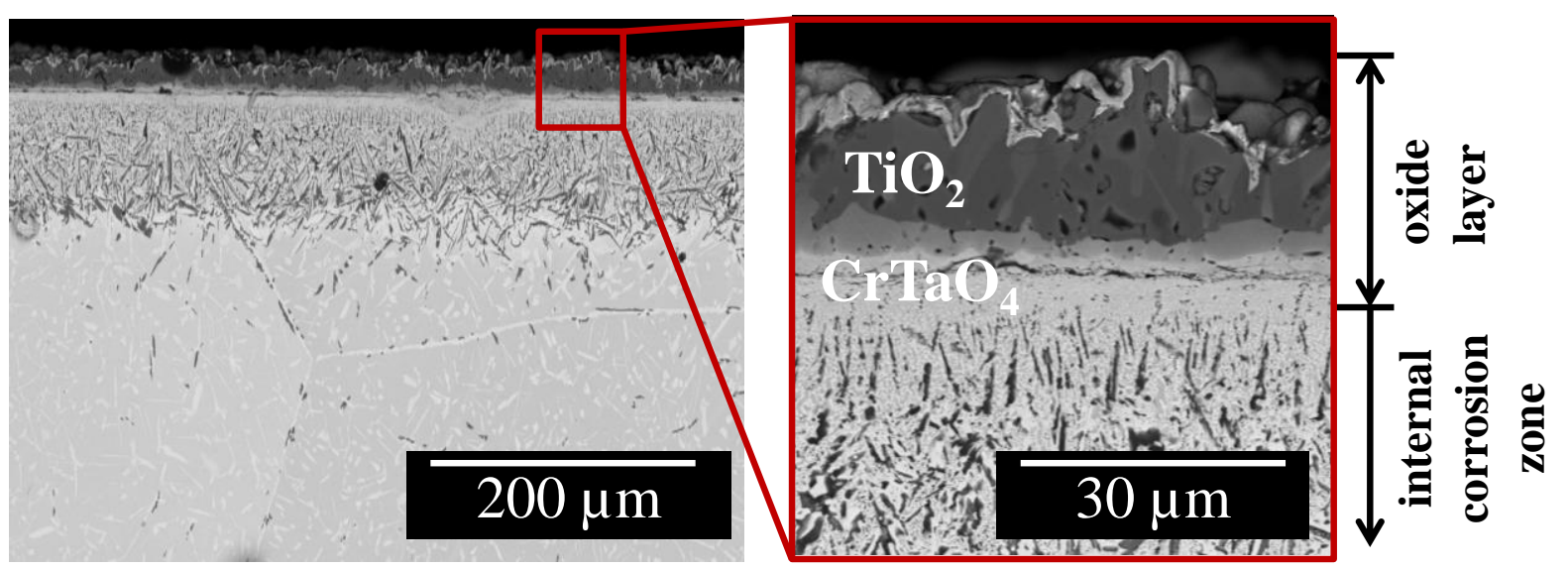

a

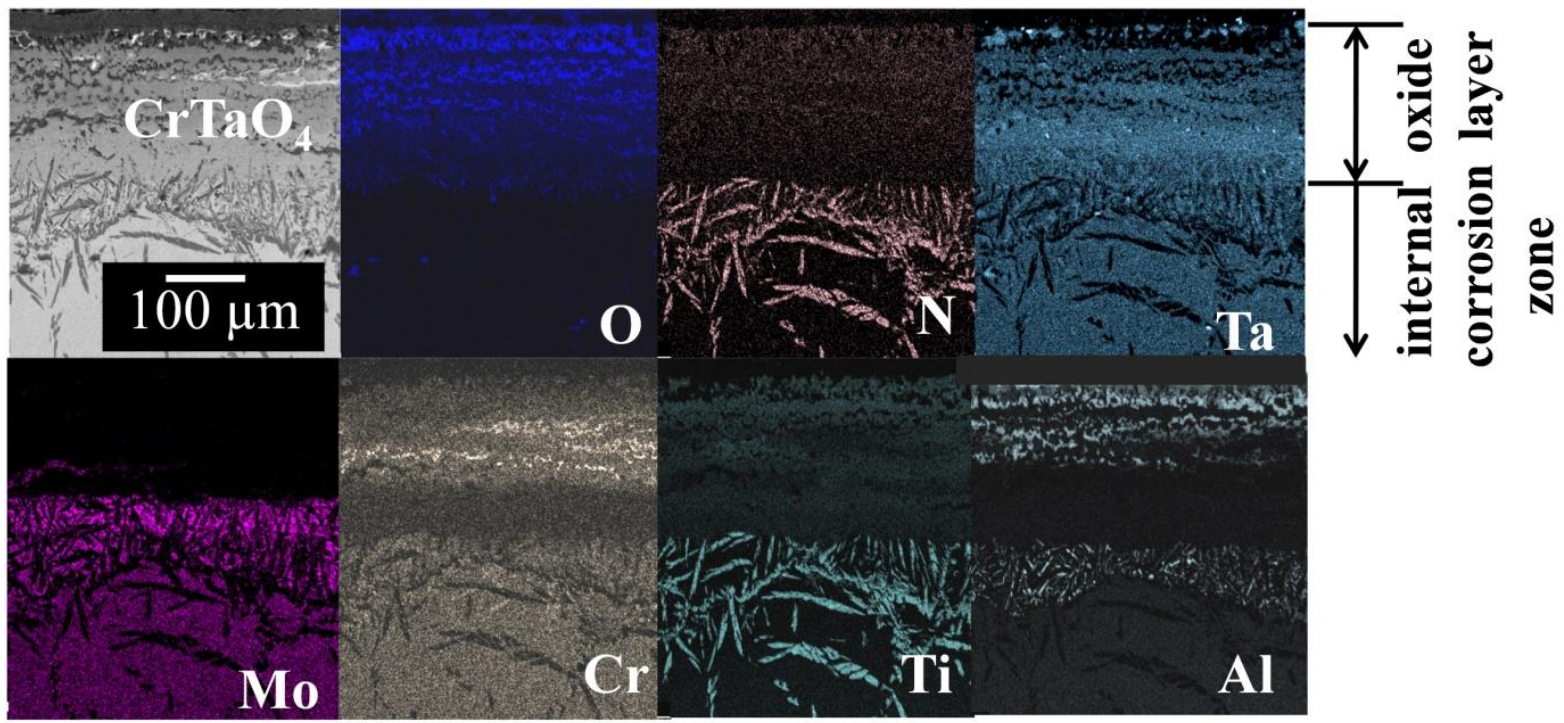

b

Fig. 3: Oxide scales formed on the alloy Ta-Mo-Cr-Ti-Al after $12 \mathrm{~h}$ oxidation. a, cross-section after oxidation at $1300^{\circ} \mathrm{C}$. b, cross-section and EDX analysis after oxidation at $1500^{\circ} \mathrm{C}$

Based on the results presented in Fig. 2, the parabolic oxidation constants $k_{p}$ were calculated according to the equation (1). Fig. 4 compares the determined parabolic growth rate constants of $\mathrm{CrTaO}_{4}$ to those of the well-known and widely applied protective oxides $\mathrm{Al}_{2} \mathrm{O}_{3}$ [28], $\mathrm{Cr}_{2} \mathrm{O}_{3}$ [28], and $\mathrm{SiO}_{2}$ [29]. While chromia-forming alloys are often used, their thermal capability is limited to temperatures below $1050^{\circ} \mathrm{C}$, as gaseous $\mathrm{CrO}_{3}$ evaporates above this critical temperature resulting in a continuous mass loss and inacceptable corrosion rate [30]. While silica exhibits low growth rates at very high temperatures, protective scales form only at temperatures above $800^{\circ} \mathrm{C}$. At lower temperatures, due to sluggish diffusion the slow growth rate of $\mathrm{SiO}_{2}$ prevents the development of a continuous layer leading to the formation of mixed non-protective oxides [31]. This effect and the additional risk that $\mathrm{Si}$ at the concentrations required for a reliable $\mathrm{SiO}_{2}$ formation often embrittles alloys by the formation of intermetallic compounds, i.e. silicides, explains, why till date no structural high temperature alloys rely on

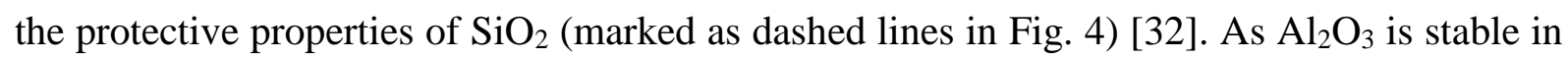


a wide temperature range even in aggressive environments, such as wet air or sulfidizing environments, many technical components, including turbine blades, are protected by $\mathrm{Al}_{2} \mathrm{O}_{3}$ scales [33].

$$
\left(\frac{\Delta m}{A}\right)^{2}=k_{p} \cdot t
$$

Surprisingly, while the growth rates of $\mathrm{CrTaO}_{4}$ are only marginally higher than those of $\mathrm{Al}_{2} \mathrm{O}_{3}$ at temperatures up to $1300^{\circ} \mathrm{C}$, they become competitive beyond that limit. Furthermore, the oxide $\mathrm{CrTaO}_{4}$ seems to be unprecedentedly stable and protective over a wide temperature range from $500^{\circ} \mathrm{C}$ to $1500^{\circ} \mathrm{C}$. While the formation of a dense and protective $\mathrm{Al}_{2} \mathrm{O}_{3}$ layer can be easily realized on Ni-based alloys even at low Al concentrations [24], no dense alumina scale could be obtained on RM-based alloys so far. Moreover, the high Al concentrations required for $\mathrm{Al}_{2} \mathrm{O}_{3}$ scale formation lead to the appearance of undesired, brittle phases [34]. On the negative side, our equiatomic alloy Ta-Mo-Cr-Ti-Al is brittle below $1000^{\circ} \mathrm{C}$. Furthermore, the integrity of the metallic substrate is a matter of concern if thermal cycling is applied. Our very recent studies, though, show that non-equiatomic alloys based on the system Ta-Mo-Cr$\mathrm{Ti}-\mathrm{Al}$ even with substantial amounts of $\mathrm{Cr}$ and $\mathrm{Al}$ are ductile at room temperature. Mechanical properties of Ta-Mo-Cr-Ti-Al alloys are, however, beyond the scope of this work and will be presented and discussed in a follow-up paper.

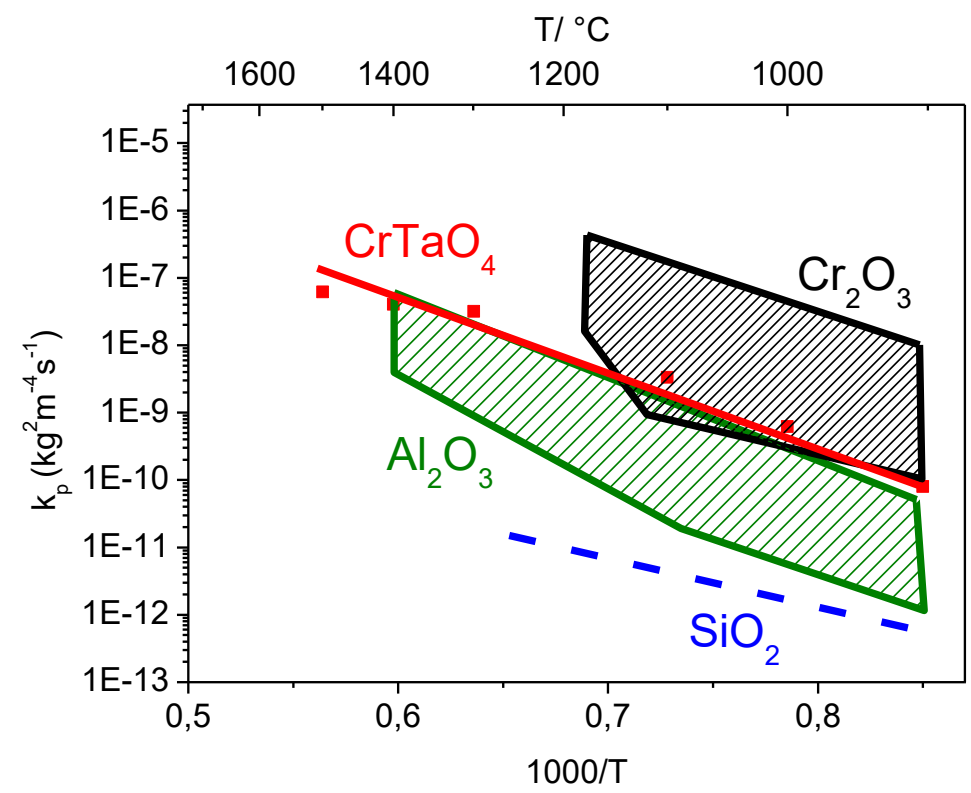

Fig. 4: Comparison of the parabolic oxidation constants of $\mathrm{CrTaO}_{4}$ on Ta-Mo-Cr-Ti-Al with those of approved protective oxides $\mathrm{Cr}_{2} \mathrm{O}_{3}, \mathrm{SiO}_{2}$ and $\mathrm{Al}_{2} \mathrm{O}_{3}$, after [28] and [29]

It is by no means surprising that the excellent high-temperature corrosion resistance of the $\mathrm{CrTaO}_{4}$ is poorly explored since the rather high Ta concentrations employed here are not common in high temperature structural alloys. Though the oxide $\mathrm{CrTaO}_{4}$ was occasionally observed in selected Ni-based superalloys [35], the formation of this oxide on the RHEA TaMo-Cr-Ti-Al reveals its unique beneficial properties clearly. Overall, our approach reveals a new way to protect RM-based alloys provided they contain sufficient concentrations of the refractory elements $\mathrm{Ta}$ and $\mathrm{Cr}$. This concept described might pave the way to develop a new 
class of high melting point, oxidation resistant RHEA being able to serve as novel structural materials for operation at ultrahigh temperatures beyond $1300^{\circ} \mathrm{C}$.

\section{Conclusions}

Our contribution clearly shows that the oxide $\mathrm{CrTaO}_{4}$ formed on the equiatomic high entropy alloy Ta-Mo-Cr-Ti-Al possesses protective properties. The oxide $\mathrm{CrTaO}_{4}$ possesses a number of unique properties that are highly important for the development of new RM-based high temperature structural materials: (i) the oxide $\mathrm{CrTaO}_{4}$ forms in a wide temperature range from $500^{\circ} \mathrm{C}$ to $1500^{\circ} \mathrm{C}$ exhibiting low growth rates, (ii) $\mathrm{CrTaO}_{4}$ seems to possess high adhesive properties (iii) since the oxide $\mathrm{CrTaO}_{4}$ is prone to solve other metallic components, a harmful competition between oxides can be avoided, (iv) the protectiveness of RM-based alloys can be realized if alloys contain required concentrations of $\mathrm{Cr}$ and $\mathrm{Ta}$.

\section{Acknowledgements}

The financial support by Deutsche Forschungsgemeinschaft (DFG) is gratefully acknowledged. We would like to thank Dr. Julian Mueller (Micro- and Nanoanalytics Group, Institute of Materials Science, University of Siegen) for providing the Ni-based alloy CMSX4. Part of this work was performed at the Micro- and Nanoanalytics Facility (MNaF) of the University of Siegen.

\section{References}

[1] J.R. DiStefano, B.A. Pint, J.H. DeVan, Oxidation of refractory metals in air and low pressure oxygen gas, Int. J. Refract. Metals Hard Mater. 18 (2000) 237-243. https://doi.org/10.1016/S0263-4368(00)00026-3

[2] E.A. Gulbransen, Thermochemistry and the oxidation of refractory metals at high temperature, Corrosion 26 (1970) 19-28. https://doi.org/10.5006/0010-9312-26.1.19

[3] V. Soni, O.N. Senkov, B. Gwalani, D. Miracle, R. Banerjee, Microstructural design for improving ductility of an initially brittle refractory high entropy alloy, Sci Rep. 8, 8816. https://doi.org/10.1038/s41598-018-27144-3

[4] H.W. Yao, J.W. Qiao, J.A. Hawk, H.F. Zhou, M.W. Chen, M.C. Gao, Mechanical properties of refractory high-entropy alloys: Experiments and modeling, J. Alloy Compd. 696 (2017) 1139-1150. https://doi.org/10.1016/j.jallcom.2016.11.188

[5] C.H. Chang, M.S. Titus, J.W. Yeh, Oxidation behavior between 700 and $1300^{\circ} \mathrm{C}$ of refractory TiZrNbHfTa high entropy alloys containing aluminium, Edv. Eng. Mater. 20 (2018) 1700948-1-8. https://doi.org/10.1002/adem.201700948

[6] S. Sheikh, M.K. Bijaksana, A. Motallebzadeh, S. Shafeie, A. Lozinko, L. Gan, T.K. Tsao, U. Klement, D. Canadinc, H. Murakami, S. Guo, Accelerated oxidation in ductile refractory high entropy alloys, Intermetallics $97 \quad$ (2018) 58-66. https://doi.org/10.1016/j.intermet.2018.04.001 
[7] K.C. Lo, A.C. Yeh, Murakami, H., Microstructural investigation of oxidized complex refractory high entropy alloys, Mater. Trans. 59 (2018) 556-562. https://doi.org/10.2320/matertrans.MJ201611

[8] S. M. Liu, H.M. Wang, S.Q. Zhang, H.B. Tang, A.L. Zhang, Microstructure and oxidation behavior of new refractory high entropy alloys, J. Alloy Compd. 583 (2014) 162-169. https://doi.org/10.1016/j.jallcom.2013.08.102

[9] T.M. Butler, K.J. Chaput, Native oxidation resistance of Al20Nb20Ta10Ti30Zr10 refractory complex concentrated alloy (RCCA), J. Alloy Compd. 787 (2019) 606-617. https://doi.org/10.1016/j.jallcom.2019.02.128

[10] O.N. Senkov, S.V. Senkova, D.M. Dimiduk, C. Woodward, D.B. Miracle, Oxidation behavior of a refractory NbCrMo0.5Ta0.5TiZr alloy, J. Mater. Sci. 47 (2012) 6522-6534. https://doi.org/10.1007/s10853-012-6582-0

[11] T.M. Butler, K.J. Chaput, J.R. Dietrich, O.N. Senkov, High temperature oxidation behaviors of equimolar $\mathrm{NbTiZrV}$ and $\mathrm{NbTiZrCr}$ refractory complex concentrated alloys $\begin{array}{llllll}\text { (RCCAs), J. } & \text { Alloy } & \text { Compd. } & 729 & \text { (2017) }\end{array}$ https://doi.org/10.1016/j.jallcom.2017.09.164

[12] G.T.J. Mayo, W.H. Shepherd, A.G. Thomas, Oxidation behavior of niobium-chromium alloys, J. Less Common Met. 2 (1960) 223-232. https://doi.org/10.1016/0022$\underline{\text { 5088(60)90016-3 }}$

[13] M.P. Brady, P.F. Tortorelli, L.R. Walker, Correlation of alloy microstructure with oxidation behavior in chromia-forming intermetallics reinforced $\mathrm{Cr}$ alloys, Mater. High Temp. 17(2) (2000) 235-241. doi:10.1179/mht.2000.17.2.009

[14] M.P. Brady, P.F. Tortorelli, E.A. Payzant, L.R. Walker, Oxidation behavior of C2N, $\mathrm{CNbN}$ and $\mathrm{CrTaN}$ phase mixtures formed on nitride $\mathrm{Cr}$ and Laves-reinforced $\mathrm{Cr}$ alloys, Oxid. Met 61 (2004) 379-401. https://doi.org/10.1023/B:OXID.0000032330.95411.ec

[15] A. Bhowmik, H.T. Pang, I. Edmonds, C.M. Rae, Effect of silicon additions on the high temperature oxidation behavior of Cr-Cr2Ta alloys, Intermetallics, 32 (2013) 373-383, doi: $\underline{10.1016 / j . i n t e r m e t .2012 .09 .013 ~}$

[16] K.C. Lo, Y.J. Chang, H. Murakami, J.W. Yeh, A.C.Yeh, An oxidation resistant refractory high entropy alloy protected by $\mathrm{CrTaO}_{4}$-based oxide, Scientific Reports, 9 (2019) 7266. doi:10.1038/s41598-019-43819-x

[17] T. Maruyama, K. Yanagihara, High temperature oxidation and pesting of $\mathrm{Mo}(\mathrm{Si}, \mathrm{Al}) 2$, Mater. Sci. Eng., A 1 (1997) 828-841. https://doi.org/10.1016/S0921-5093(97)00673-4

[18] R.M. Dasary, S.K. Varma, Short-term oxidation response of Nb-15Re-15Si-10Cr-20Mo alloy, J. Mater. Res. Technol. 3 (2014) 25-34. https://doi.org/10.1016/j.jmrt.2013.10.006 
[19] F. Mueller, B. Gorr, H.-J. Christ, J. Mueller, B. Butz, H. Chen, A. Kauffmann, M. Heilmaier, On the oxidation mechanism of refractory high entropy alloys, in press, https://doi.org/10.1016/j.corsci.2019.108161

[20] A.S. Khanna, Introduction to high temperature oxidation and corrosion, ASM International, Delhi, 2002

[21] S.T. Liang, H.L. Zhang, M.TlLuo, K.J. Luo, P. Li, H.B. Xu, Y. Zhang, Colour performance investigation of a $\mathrm{Cr}_{2} \mathrm{O}_{3}$ green pigment prepared via the thermal decomposition of $\mathrm{CrOOH}$, Ceram. Int., 40 (2014) 4367-4373, doi.org/10.1016/j.ceramint.2013.08.107

[22] S.J. Grisaffe, D.L. Deadmore, W.A. Sanders, Furnace and high velocity oxidation of aluminide-coated cobalt superalloy WI-52, NASA Technical Note D-5834, 1970

[23] C.H. Chang, M. Titus, J.W. Yeh, Oxidation behaviour between 700 and $1300^{\circ} \mathrm{C}$ of refractory TiZrNbHfTa high entropy alloys containing aluminium, Edv. Eng. Mater, 20 (2018) 1700948, doi: 10.1002/adem.201700948

[24] C.S. Giggins, F.S. Pettit, Oxidation of Ni-Cr-Al alloys between $1000^{\circ}$ and $1200^{\circ} \mathrm{C}$, J. Electrochem. Soc. 18 (1971) 1782-1790. doi: 10.1149/1.2407837

[25] M.H. Li, X.F. Sun, T. Jin, H.R. Guan, Z.Q. Hu, Oxidation behavior of a single crystal Nibase superalloy in air - II: At 1000, 1100, and 1150 ${ }^{\circ} \mathrm{C}$, Oxid. Met. 60 (2003) 195-210. https://doi.org/10.1023/A:1024629716452

[26] A. Petersen, H. Mueller-Buschbaum, A contribution of ternary oxides of the AMO4-type $\left(\mathrm{A}=\mathrm{Ti}^{3+}, \quad \mathrm{Cr}^{3+} ; \mathrm{M}=\mathrm{Nb}^{5+}, \quad \mathrm{Ta}^{5+}\right), \quad \mathrm{Z}$. Anorg. Allg. Chem. 609 (1992) 51-54 https://onlinelibrary.wiley.com/doi/pdf/10.1002/zaac.19926090309

[27] A. Kirnbauer, C. Spadt, C. M. Koller, S. Kolozsvari, P.H. Mayrhofer, High-entropy oxide thin films based on Al-Cr-Nb-Ta-Ti, Vacuum $168 \quad$ (2019) 108850 https://doi.org/10.1016/j.vacuum.2019.108850

[28] H. Hindam, D.P. Whittle, Microstructure, adhesion and growth kinetics of protective scales on metals and alloys, Oxid. Met. 18 (1982) 245-284. https://doi.org/10.1007/BF00656571

[29] J.L. Smialek, G.M. Meier, Superalloys II: High Temperature Materials for Aerospace and Industrial Power, John Wiley \& Sons, Hoboken, USA, 1987.

[30] P. Kofstad, K.P. Lillerud, Chromium transport through Cr2O3 scales.I. On lattice diffusion of chromium, Oxid. Met. $17 \quad$ (1982) 177-194. https://doi.org/10.1007/BF00738381

[31] N.Birks, G.H. Meier, F.S. Pettit, Introduction to the High Temperature Oxidation of Metals, Cambridge University Press, Cambridge, 2006. 
[32] H.J. Grabke, M. Schuetze, Oxidation of Intermetallics, WILEY-VCH Verlag, Weinheim, 1998.

[33] S. Han, D.J. Young, Oxidation - nitridation of Ni-Cr-Al alloys, J. Mater .Res. 7 (2004) 11-16. http://dx.doi.org/10.1590/S1516-14392004000100003

[34] O.N.Senkov, D.B. Miracle, K.J. Chaput, Development and exploration of refractory high entropy alloys - A review, J. Mater. Res. 33 (2018) 3092-3128. https://doi.org/10.1557/jmr.2018.153

[35] W. Ren, B. Ding, F. Ouyang, Y. Zhong, The influence of CrTaO4 layer on the oxidation behavior of a directionally solidified nickel-based superalloy at $850-900^{\circ} \mathrm{C}$, J. Alloy Compd. 724 565-574 (2017). https://doi.org/10.1016/j.jallcom.2017.07.066 